\title{
The Other Side(s) of Health Informatics
}

\author{
Lincoln de Assis Moura Jr., President of IMIA \\ Director, AM eHealth - Porto Alegre, RS, Brazil
}

When compared to other fields of the human sciences, Health Informatics is very young. The history of terms used to represent our field bears witness to that: Medical Computing, Medical Informatics, Health and Biomedical Informatics, and more recently eHealth, are but a few examples to show our field is still evolving. The idea here is not to create an argument about how expressive such terms are, but simply to emphasize how immature the field is they describe is. A very interesting and current discussion on this subject has been recently organized by Professor Reinhold Haux [1] on a paper by Peter L. Elkin, Steven H. Brown, and Graham Wright [2].

Health Informatics has evolved from very disruptive, though stand-alone, computer applications to nation-wide eHealth structures, programs, and strategies. As anticipated by Professor Antoine Geissbuhler in his Yearbook 2013 President's Statement [3] the World Health Assembly (WHA) passed in May 2013 its Resolution WHA66.24, urging member countries to embrace eHealth as an essential enabler of better health systems and health care services. That resolution [4] recognizes the need for the adoption of health informatics standards, road maps, strategies, legislation, and collaboration with relevant stakeholders. Even before WHA's resolution on eHealth, many countries undertook the mission of designing and deploying eHealth strategies, with varied levels of execution and success $[5,6,7,8]$. The WHA resolution is a landmark as it reflects the worldwide perception that eHealth can change Health for better.

In a world that is undergoing drastic changes caused by smart phones, tablets, social media, cloud computing, big data, bitcoins, and other disruptive technologies and services, it is only natural that even the layman raises his expectation regarding Health Informatics improving health care delivery, as it has happened in other areas, from banking to public services. It is important, though, that we, health informaticians and members of the IMIA community, do recognize that despite the evolution in knowledge, data gathering, and devices, the impact of eHealth on health care delivery falls short of almost everyone's expectations - even in the developed world. Health care professionals, health managers, top-level civil servants, politicians, investors, and patients often face frustration with the results of their personal, political, financial, and emotional investment in Health Informatics [10].

Getting insight into such limitations is the main focus of this statement. One way to do this is to approach the issues related to the deployment of eHealth in complex settings. The ITU-WHO Toolkit [11] does a wonderful job at this, by proposing seven major eHealth components to be considered when designing a National eHealth Strategy. They are: a) leadership and governance; b) strategy and investment; c) services and applications; d) standards and interoperability; e) infrastructure; f) legislation, policy and compliance; and g) workforce. Obviously, each one of those pillars can be decomposed in several others.

Generally speaking, our community tends to focus on components (c) and (d), as core technical components. Most of us also approach $(\mathrm{g})$ - workforce, as education and capacity building are widely recognized as essential for any Health Informatics project. Infrastructure (e) is, likewise, part of our concerns.

Aspects such as leadership, change management, governance, strategy, investment, legislation, policy, and compliance have not been as widely and as deeply studied by our community. It is true that in small settings or in tightly focused Health IT projects, these concepts may not be essential, but any project that aims at becom-

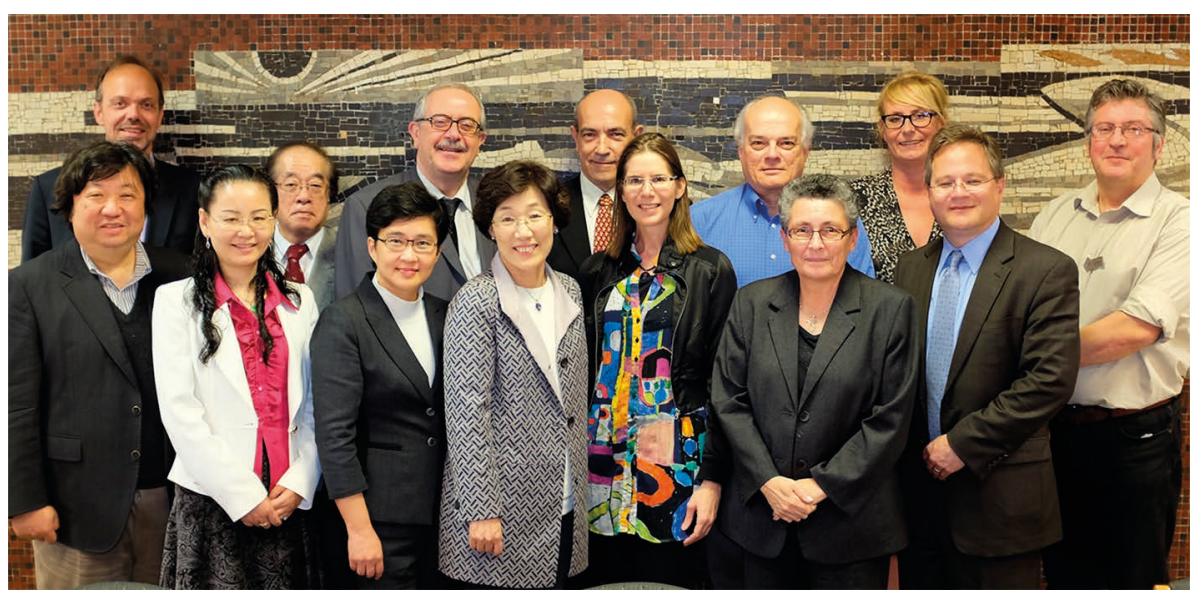

Fig. 1 IMIA Board at IMIA Board Meeting in April 2014 in Budapest 
ing mainstream or at escalating to cover a country or a wide region should consider them thoroughly, if the goals of usefulness, adoption, reach, scale, reusability, and sustainability are to be attained.

If ITU-WHO's seven pillars are recognized as important, then a relevant challenge for us is to promote the balance among these pillars. We need, of course, to continue with the development of innovative core HIT knowledge, techniques, and devices, but we also need to support and promote research in disruptive strategies and policies that will help eHealth to be widely adopted and eventually transparently embedded in our daily activity. This is a complex endeavor and one that is slightly removed from our usual paths. If we are to overcome the more organizational aspects above and transform Health and Health Care for real and for better, we need to think outside of our own box and do things in a different way. We need to look close- ly at the organizational complexity, get familiar with it, understand it thoroughly, and then propose and exercise mechanisms to deal with it.

The first step towards changing ourselves is gaining awareness. It is time we help Health Informatics to firmly embrace non-technical issues and create a critical mass around them.

\section{References}

1. Geissbuhler A, Hammond WE, Hasman A, Hussein R, Koppel R, Kulikowski CA, et al. Discussion of "Biomedical Informatics: We Are What We Publish". Methods Inf Med 201352 6: 547-62.

2. Elkin PL, Brown SH, WrightG. Biomedical Informatics: We Are What We Publish. Methods Inf Med 2013 52 6: 538-46.

3. Geissbuhler A. Scaling up Health Informatics. Yearb Med Inform 2013;8:1.

4. Sixty-Sixth World Health Assembly. Resolution WHA66.24. eHealth standardization and interoperability. 27 May 2013.

5. Stroetmann KA, Artmann J, Stroetmann VN,
Protti D, Dumortier J, Giest S, et al. European countries on their journey towards national eHealth infrastructures. Final European progress report. European Comission. January 2011.

6. Canada Health Infoway Annual Report 2008/2009, Building a Healthy Legacy Together. www2. infoway-inforoute.ca/Documents/ar/Annual_Report_2008-2009_en.pdf.

7. South Africa. eHealth Strategy South Africa, 2012 - 2016. www.doh.gov.za/docs/stratdocs/2012/ eHealth_Strategy_South_Africa_2012-2016.pdf.

8. NHS Scotland - eHealth Strategy, 2011 -2017. www. scotland.gov.uk/Resource/Doc/357616/0120849.pdf.

9. Sweden - National eHealth, - the strategy for accessible and secure information in health and social care, 2011. www.cehis.se/images/uploads/ dokumentarkiv/National_eHealth_2011_eng_ rapport_111115.pdf.

10. Why the UK's GBP $12.4 \mathrm{bn}$ NHS ehealth record management system failed. www.zinc-healthcare.com/blogpost/why-theuks-nhs-ehealth-record-management-technologies-failed.

11. National eHealth strategy toolkit. www.itu.int/ pub/D-STR-E_HEALTH.05-2012. ISBN 97892 41548465 (WHO) (NLM classification: W 26.5). ISBN 9789261140519 (ITU). 